\title{
Ferroelectric Behavior In Fluorinated Aliphatic Polyurethanes
}

\author{
Ambalangodage Champa JAYASURIYA, Shigeru TASAKa, Toshikatu SHouko, \\ and Norihiro INAGAKI \\ Department of Materials Science, Graduate School of Electronic Science and \\ Technology, Faculty of Engineering, Shizuoka University, \\ 3-5-1, Johoku, Hamamatsu 432, Japan
}

(Received April 18, 1994)

\begin{abstract}
Ferroelectric behavior was investigated for fluorinated polyurethanes with oddodd or odd-even numbers of $\mathrm{C}$ atoms; poly(hexafluoro-1,5-pentane-heptamethylene dicarbamate) (5F,7 polyurethane) and poly(hexafluoro-1,5-pentane-hexamethylene dicarbamate) (5F,6 polyurethane). Remanent polarization and coercive field estimated from D-E hysteresis loops were $25-35 \mathrm{mC} \mathrm{m}^{-2}$ and $20-30 \mathrm{MV} \mathrm{m}^{-1}$, respectively.

KEY WORDS Fluorinated Polyurethane / Ferroelectric / Pyroelectric / Polarization / Amorphous / Hydrogen Bonding /
\end{abstract}

The investigation of ferroelectric behavior in polymer materials has received a great deal of attention from applied and fundamental point of view. ${ }^{1-7}$ Ferroelectric behavior was first found in poly(vinylidene fluoride) $\left(\mathrm{PVF}_{2}\right.$ or PVDF) and its copolymers. ${ }^{2,3}$ Recently, this property was found in Nylon 7 and Nylon $11^{4,5}$ for melt-quenched and cold-drawn samples. In polyamides with an even number of $\mathrm{CH}_{2}$ groups, namely odd nylons, the arrangement of molecular chains has been considered to result from close-packing of paraffinic chains and $\mathrm{N}-\mathrm{H}$... O hydrogen bonds. Ferroelectric polarization reversal in polyureas with odd numbers of $\mathrm{CH}_{2}$ groups has also been demonstrated. ${ }^{6}$ A ferroelectric crystal is likely to form in aliphatic polyurethanes having odd-odd and even-odd numbers of $\mathrm{CH}_{2}$ groups. ${ }^{7}$ Polyurethane with $\mathrm{NH} \cdots \mathrm{O}$ hydrogen bonds are considered to have the same behavior as polyamides or polyureas. According to X-ray diffraction measurements, the crystal structure of polyurethanes is similar to that of polyamides. ${ }^{8}$ Infrared measurements show that all the hydrogen bondings are occurred for linear polyurethanes. $^{9}$
Nylon 7 and Nylon 11 show no polarization reversal after annealing, suggesting the formation of strong hydrogen bonding in crystals. Polyureas and normal aliphatic polyurethanes (odd-even) do not show ferroelectric behavior after annealing. ${ }^{6,7}$ Therefore, polymers which have weak cohesive energy are desirable for ferroelectric polarization reversal. Fluorinated polymers generally have important features such as a) low cohesive energy, b) solubility in polar solvent, and c) chemical stability, which are favorable for the dipole rotation by electric field and the suppression of direct current (dc) conductivity. The significance of fluorinated polyurethanes compared with normal polyamides, polyureas or polyurethanes is that the hydrogen bonding of the polyurethanes can be weakened by the substitution of fluorine atoms. Hence, dipoles can be easily rotated toward the direction of electric field, even after annealing.

This paper reports the ferroelectric behavior of fluorinated polyurethanes. The formula of polyurethanes studied is $\left[\mathrm{OCH}_{2}-\left(\mathrm{CF}_{2}\right)_{3}-\right.$ $\left.\mathrm{CH}_{2}-\mathrm{OCONH}-\left(\mathrm{CH}_{2}\right)_{n}-\mathrm{NHCO}\right]_{p}$ where $n$ is an integer and represents the number of $\mathrm{CH}_{2}$ groups of diisocyanate. The polymers are 
named as $5 \mathrm{~F}, n$-polyurethane because fluorine is included in the polymers.

\section{EXPERIMENTAL}

Polyurethanes were synthesized by condensation of diol and diisocyanate as reported by Iwakura and Koyama. ${ }^{10}$ For instance 5F,6 polyurethane was prepared as follows. Approximately equal amounts of hexamethylene diisocyanate and hexafluoro 1,5 pentanediol in anisole were heated stepwise to $140^{\circ} \mathrm{C}$ for $3 \mathrm{~h}$. The reaction was gradually stopped by adding ethanol. 5F,7 polyurethane was also synthesized by the same method using heptamethylene diisocyanate synthesized by Siefken's method. ${ }^{11}$ The chemical structures of polymers obtained are given in Figure 1. Melt-cast films were obtained on conductive glass plates (ITO) by quenching in an ice bath. Aluminum electrodes was made on the surface of the cast films by vaccum evaporation. These films were subjected to electrical property measurements.

Infrared spectra were obtained with a HORIBA FT 300 with the resolution of 4 $\mathrm{cm}^{-1}$. Differential scanning calorimeter (DSC) measurements were carried out with a MAC SCIENCE DSC 3100 with a heating rate of $10^{\circ} \mathrm{Cmin}^{-1}$. X-Ray diffraction patterns were obtained with a RIGAKU RAD-B diffractometer using $\mathrm{Cu} K_{\alpha}$ radiation. Dielectric measurements were performed in vacuum with a HP 4285 LCR meter. D versus E hysteresis

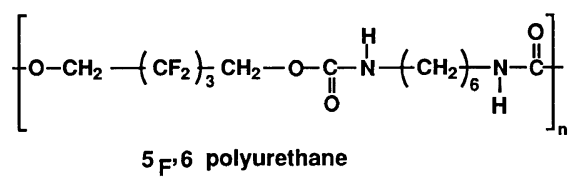

$$
\begin{aligned}
& \left.\left.\left[0-\mathrm{CH}_{2}-\left(\mathrm{CF}_{2}\right)_{3} \mathrm{CH}_{2}-\mathrm{O}-\mathrm{C}-\stackrel{\mathrm{C}}{\mathrm{N}}+\mathrm{CH}_{2}\right)_{7} \underset{\mathrm{H}}{\mathrm{N}-\mathrm{O}}\right]_{\mathrm{C}}^{\mathrm{C}}\right]_{\mathrm{n}} \\
& { }_{5}, 7 \text { polyurethane }
\end{aligned}
$$

Figure 1. Chemical structures of fluorinated polyurethanes. characteristics were measured by applying a triangular electric field with a frequency of $0.03 \mathrm{~Hz}$. Reversible pyroelectric current and thermally stimulated depolarization current (TSC) for poled samples were obtained simultaneously from the current through the electrode irradiated by a pulsed semiconductor laser $(670 \mathrm{~nm}, 3 \mathrm{~mW}, 10 \mathrm{~Hz})$ during heating $\left(3^{\circ} \mathrm{C} \min ^{-1}\right)$.

\section{RESULTS AND DISCUSSION}

Thermal properties of polyurethanes are given in Table I, obtained from DSC measurements. The melting and glass transition temperatures in fluorinated polyurethanes were lower than those of normal aliphatic polyurethanes. ${ }^{7}$ This may be attributed to weakened hydrogen bonding with expansion of crystal lattice containing fluorine atoms with large van der Waals radius. The transition temperatures strongly depend on thermal history. For example, the crystallization peak and glass transition are not observed in slowlycooled samples.

Figure 2 shows the FTIR spectra of 5F,7 polyurethane. This spectra gives bands corresponding to all bonds of $5 \mathrm{~F}, 7$ polyurethane. There are two peaks at 3450 and $3342 \mathrm{~cm}^{-1}$ due to the $\mathrm{N}-\mathrm{H}$ bonds. A free $\mathrm{N}-\mathrm{H}$ stretching vibration band $\left(3447 \mathrm{~cm}^{-1}\right)$ and hydrogen bonded $\mathrm{N}-\mathrm{H}$ band (near $3300 \mathrm{~cm}^{-1}$ ) appear in the range of the stretching vibration $\mathrm{N}-\mathrm{H}$ groups for aliphatic polyurethane. ${ }^{9}$ The band at $3450 \mathrm{~cm}^{-1}$ may be a free $\mathrm{N}-\mathrm{H}$ stretching band and the hydrogen bonded $\mathrm{N}-\mathrm{H}$ band

Table I. Thermal properties of fluorinated polyurethanes obtained from DSC at a heating rate of $10^{\circ} \mathrm{C} \mathrm{min}^{-1}$ a

\begin{tabular}{cccc}
\hline \multicolumn{1}{c}{ Sample } & $T_{\mathrm{g}} /{ }^{\circ} \mathrm{C}$ & $T_{\mathrm{c}} /{ }^{\circ} \mathrm{C}$ & $T_{\mathrm{m}} /{ }^{\circ} \mathrm{C}$ \\
\hline 5F,6 Polyurethane & 12 & 70 & 92 \\
5F,7 Polyurethane & -5 & - & 63
\end{tabular}

a $T_{\mathrm{g}}$, glass transition temperature; $T_{\mathrm{c}}$, crystallization temperature; $T_{\mathrm{m}}$, melting temperature. 


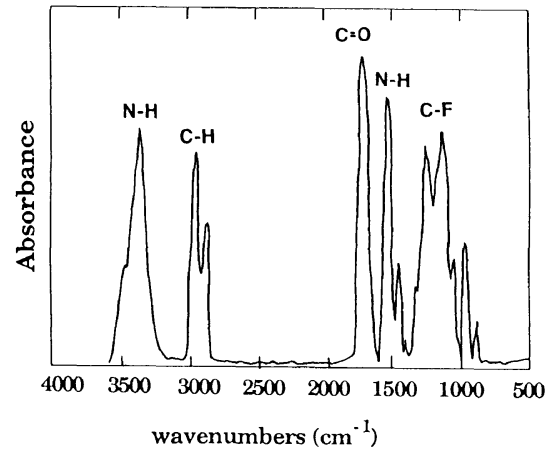

Figure 2. FTIR spectra for a quenched sample of $5 \mathrm{~F}, 7$ polyurethane.

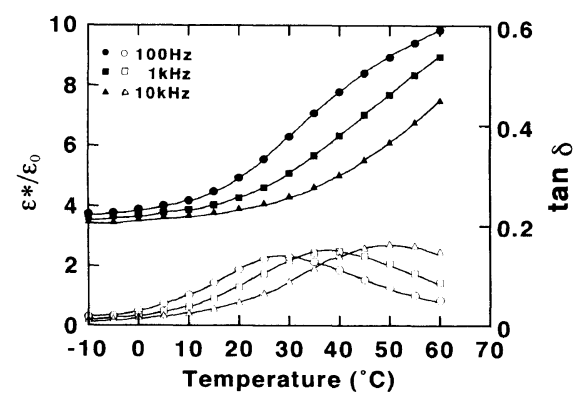

Figure 3. Temperature dependence of dielectric constant and dissipation factor for quenched samples in $5 \mathrm{~F}, 7$ polyurethane.

around $3342 \mathrm{~cm}^{-1}$ is attributed to ordered and disordered hydrogen bonding in polyurethane. ${ }^{12}$ The wavenumber of the hydrogen bonded $\mathrm{N}-\mathrm{H}$ band in fluorinated polyurethane is higher than that of normal aliphatic polyurethanes. It is corresponded to weakenning of hydrogen bonding by substitution of fluorine atoms in $\mathrm{CH}_{2}$ groups.

Figure 3 shows the temperature dependence of the dielectric constant $\left(\varepsilon^{*} / \varepsilon_{0}\right)$ and dissipation factor $(\tan \delta)$ of $5 \mathrm{~F}, 7$ polyurethane in the temperature range from -10 to $60^{\circ} \mathrm{C}$ at three different frequencies. The dielectric constant $\left(\varepsilon^{*} / \varepsilon_{0}\right)$ starts to rise gradually from the glass transition temperature $\left(-5^{\circ} \mathrm{C}\right)$. The crystallinity of the measured sample is probably low. However the sample participates in aggregation of the inter-chain hydrogen bonding. Temperature dependence of dielectric relaxation

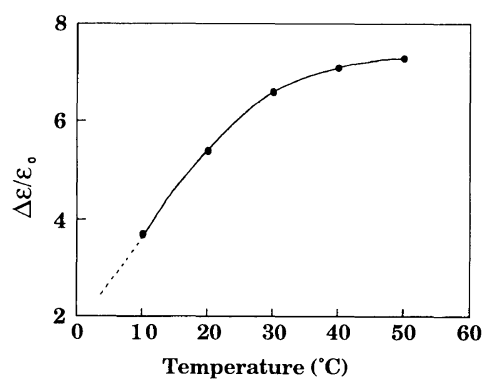

Figure 4. Temperature dependence of dielectric relaxation strength obtained by Cole-Cole plots in 5F,7 polyurethane.

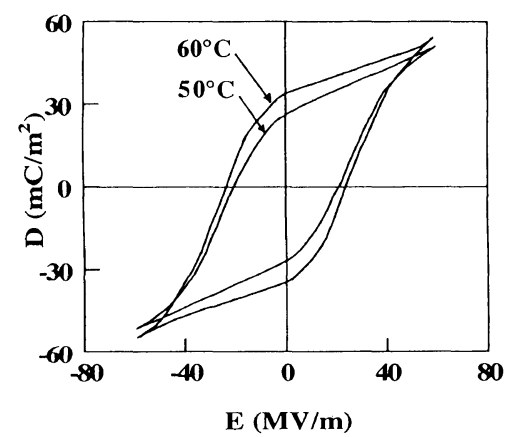

Figure 5. D-E hysteresis curves of a) $5 \mathrm{~F}, 6$ polyurethane at 50 and $60^{\circ} \mathrm{C}$ b) $5 \mathrm{~F}, 7$ polyurethane at $50^{\circ} \mathrm{C}$ with the frequency of $0.03 \mathrm{~Hz}$.

strength obtained from Cole-Cole plots for $5 \mathrm{~F}, 7$ polyurethane is shown in Figure 4 . The dielectric relaxation strength increases with temperature from the glass transition temperature and saturates near the melting point $(\Delta \varepsilon /$ $\varepsilon_{0}=7.3$ at $50^{\circ} \mathrm{C}$ ). The dielectric increment of this sample due to free rotation of dipoles calculated from Onsager's equation was $\Delta \varepsilon / \varepsilon_{0}=$ 7-8. Therefore, the dipoles of polyurethanes at least behave as a free rotation model near the melting temperature. The dielectric relaxation of these samples is possibly due to the microbrownian like motion having a wide relaxation time distribution from hydrogen bondings.

$D$ versus $E$ hysteresis is obtained by integrating the corrected current density with respect to time. Figure 5 shows D-E hysteresis loops for $5 \mathrm{~F}, 6$ polyurethane and $5 \mathrm{~F}, 7$ polyurethane above the glass transition temperature at 60 


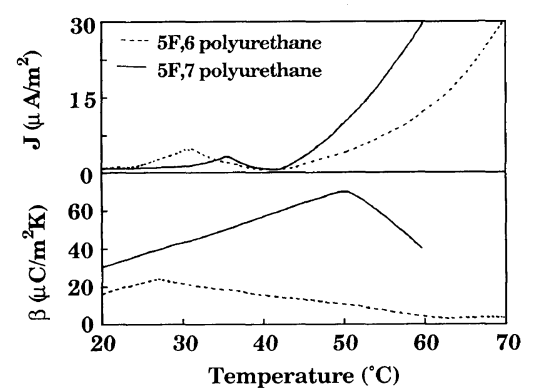

Figure 6. Thermally stimulated current (TSC) and pyroelectric constant $(10 \mathrm{~Hz})$ for $5 \mathrm{~F}, 6$ and $5 \mathrm{~F}, 7$ polyurethanes.

and $50^{\circ} \mathrm{C}$. In the case of $5 \mathrm{~F}, 6$ polyurethane, the value of the remanent polarization $(\mathrm{Pr})$ determined from the intercept of each loops with the $\mathrm{D}$-axis are 35 and $28 \mathrm{mC} / \mathrm{m}^{-2}$ for the temperatures of 60 and $50^{\circ} \mathrm{C}$, respectively. These curves are essentially the same as those of PVDF or odd nylons. Reproducibility of $P_{\mathrm{r}}$ depended on the thermal history, crystallinity and molecular orientation of samples. Remanent polarization and coercive field estimated from $\mathrm{D}-\mathrm{E}$ hysteresis loops of $5 \mathrm{~F}, 7$ polyurethane were $32 \mathrm{mC} \mathrm{m}^{-2}$ and $29 \mathrm{MV} \mathrm{m}^{-1}$ at $50^{\circ} \mathrm{C}$. These hysteresis loops were observed even after annealing.

The dipole moment of the urethane group is about 2.8 Debye, smaller than those of the amide group (3.7 Debye) or urea group (4.9 Debye). ${ }^{4,6}$ Remanent polarization by the dipole orientation of the fluorinated polyurethane groups was estimated about $30-35 \mathrm{mC} / \mathrm{m}^{-2}$ in these polymers. This value agrees with the remanent polarization obtained from this experiment.

Figure 6 shows the temperature dependence of the TSC curve and pyroelectric constant $(\beta)$ for both polymers. Both polymer samples were poled under a field of $40 \mathrm{MV} \mathrm{m}^{-1}$ at $45^{\circ} \mathrm{C}$ which is higher than the glass transition temperature of the polymers. For 5F, 6 polyurethane, the TSC curve shows a peak at about $31^{\circ} \mathrm{C}$, and increases above $40^{\circ} \mathrm{C}$. The pyroelectric activity gradually decreases above $28^{\circ} \mathrm{C}$. Therefore, pyroelectric activity is un- stable above the glass transition temperature $\left(12^{\circ} \mathrm{C}\right)$ but does not diminish to zero at the glass transition temperature. From these results, it may be considered that pyroelectric activity may originate from the remanent polarizations in the crystal region. The TSC curve of $5 \mathrm{~F}, 7$ polyurethane shows a small peak at $36^{\circ} \mathrm{C}$, which increases above $40^{\circ} \mathrm{C}$. The pyroelectric constant increases gradually with temperature close to the melting temperature. Pyroelectric activity in $5 \mathrm{~F}, 7$ polyurethane is also due to remanent polarization in crystalline phases but the pyroelectric activity of $5 \mathrm{~F}, 7$ polyurethane is more stable than that of $5 F, 6$ polyurethane. Remanent polarization in fluorinated polyurethanes may be not only from the crystallization phase, but also from the amophous phase with hydrogen bonded dipoles, stable above the glass transition temperature.

$\mathrm{X}$-Ray diffraction patterns of quenched samples of 5F,6 polyurethane and 5F,7 polyurethane are quite similar. Both polyurethanes show main broad peaks around $2 \theta=20^{\circ}$ and, another peak around $2 \theta=5^{\circ}$. The latter corresponds to fiber axis periodicity. The melt cast samples probably have disordered crystal structures. Saito et al. reported ${ }^{8}$ on the structures of aliphatic polyurethanes that crystal packing of odd-even and even-even polyurethanes is non polar and similar to that of polyamides. However, structural data of crystal in the fluorinated polyurethanes are not available at present. From analogy of odd nylons, ${ }^{13}$ odd-polyurethanes such as $5 \mathrm{~F}, 7$ polyurethane may consist of parallel packing of polar chains. Although 5F,6 polyurethane have non-polar chains in trans conformation, it has possibly polar crystals by applying a high electric field because of weaker hydrogen bonding. Smectic structure of nylon 11 and consequent weakening of the interchain amide hydrogen bond are induced by quenching. ${ }^{14}$ Ferroelectric properties exist in other metastable phases of the odd nylons and possibly in amorphous regions. The strength of hydro- 
gen bonding of the polyurethanes can be weakened by the ether group in polyurethanes and substitution of fluorine atoms. Therefore, the possible origin of the ferroelectricity in fluorinated polyurethanes is likely related to the polar structure formed by hydrogen bonding and an external electric field.

Futher electrical and structural data are necessary to elucidate the origin of ferroelectricity in fluorinated polyurethanes.

\section{CONCLUSIONS}

We prepared two fluorinated linear $(5 \mathrm{~F}, 6$ and $5 \mathrm{~F}, 7)$ polyurethanes. These polyurethanes having odd-odd and odd-even number of carbon atoms showed ferroelectric D-E hysteresis loops. Ferroelectric behavior is possibly due to various hydrogen bonds in crystal and amorphous regions.

\section{REFERENCES}

1. T. T. Wang, J. M. Herbert, and A. M. Glass, "The
Application of Ferroelectric Polymers," Chapman \& Hall, New York, N.Y., 1988, p 118.

2. M. Tamura, K. Ogasawara, N. Ono, and S. Hagiwara, J. Appl. Phys., 45, 3768 (1974).

3. T. Furukawa, Phase Trans., 18, 143 (1989).

4. J. W. Lee, Y. Takase, B. A. Newmann, and J. I. Scheinbeim, J. Polym. Sci., Polym. Phys. Ed., 29, 273 (1991).

5. J. W. Lee, Y. Takase, B. A. Newmann, and J. I. Scheinbeim, J Polym. Sci., Polym. Phys. Ed., 29, 279 (1991).

6. S. Tasaka, T. Shouko, and N. Inagaki, Jpn. J. Appl. Phys., 31, L1086 (1992).

7. S. Tasaka, T. Shouko, K. Asami, and N. Inagaki, Jpn. J. Appl. phys., 33, 1376 (1994).

8. Y. Saito, S. Nansai, and S. Kinoshita, Polym. J., 3, 113 (1972).

9. T. Tanaka, T. Yokoyama, and Y. Yamaguchi, $J$. Polym. Sci., A-1, 6, 2137 (1968).

10. Y. Iwakura and R. Koyama, Kobunshi Kagaku, 9, 306 (1951) (in Japanese).

11. W. Siefken, Ann. Chem., 562, 75 (1949).

12. D. J. Skrovanek, P. C. Painter, and M. M. Coleman, Macromolecules, 19, 699 (1986).

13. Y. Kinoshita, Macromol. Chem., 33, 1 (1959).

14. E. Balizer, J. Fedderly, D. Haught, B. Dickens, and A. S. Dereggi, J. Polym. Sci., Polym. Phys. Ed., 32, 365 (1994). 